\title{
Appearance of calpain correlates with arthritis and cartilage destruction in collagen induced arthritic knee joints of mice
}

\author{
Zoltan Szomor, Katsuji Shimizu, Youichi Fujimori, Shingo Yamamoto, Takao Yamamuro
}

\begin{abstract}
Objectives-To determine the relevance of calpain in murine collagen induced arthritis (CIA) and to correlate the presence of $\mathbf{m}$-calpain with the appearance of arthritis and cartilage destruction.

Methods-The immunohistochemical appearance and localisation of $\mathbf{m}$-calpain at different stages of arthritis were analysed and compared with the histological changes occurring during type II CIA. The arthritic knee joint lavage was also examined for m-calpain by immunoelectrophoretic blotting.

Results-Immunohistochemical staining demonstrated a clear positive correlation between the appearance of $\mathrm{m}$-calpain and both a histological grade of arthritis and an acute phase of cartilage destruction. Further development of the disease showed continual presence of $\mathrm{m}$-calpain but with reduced intensity. Intra-articular inflammatory cells (mainly polymorphonuclear leucocytes, synovial lining cells, and sublining fibroblasts) were found to be the most positively stained, but extracellular localisation of m-calpain on the surface of cartilage and synovium, and in the articular cartilage matrix and chondrocyte lacunae, was also observed. In the knee joint lavage obtained at the most intensive stage of acute arthritis, m-calpain was detectable by immunoelectrophoretic blotting.

Conclusions-The findings suggest that m-calpain may act at an early phase of CIA as a matrix proteinase and take part in the destruction of articular cartilage or activate other destructive enzymes.
\end{abstract}

(Ann Rheum Dis 1995; 54: 477-483)

Articular cartilage breakdown has been considered to be one of the most significant events which occurs during the arthritic process. Current experimental evidence suggests that proteolytic pathways associated with cellular interactions play the major role in cartilage destruction. Although the precise mechanisms are not fully elucidated, matrix proteinases such as neutral metalloproteinases (including collagenases, ${ }^{12}$ stromelysins, ${ }^{3-5}$ and gelatinases, ${ }^{67}$ plasminogen activator, ${ }^{8}$ cathepsins, ${ }^{910}$ and elastase $\left.^{11}\right)$, possessing the ability to degrade cartilage matrix components, are the factors studied and implicated most frequently. It has also been demonstrated that the cellular microenvironment induced by inflammation further influences cartilage destruction..$^{9-12}$

Calpain is an interesting enzyme and unique among cysteine proteinases, as it is activated by calcium ions and it has an optimum $\mathrm{pH}$ of $7 \cdot 0-7 \cdot 5 .^{13}$ There are two forms of calpain, which differ in their calcium ion requirement for activation: $\mu$-calpain is activated by micromolar concentrations of calcium, and $\mathrm{m}$-calpain is activated by millimolar concentrations of calcium ions. Calpastatin, the specific endogenous inhibitor of calpain, is known to codistribute with calpain; ${ }^{14}$ in common with other protease systems, the balance between them influences the actual calpain activity. This regulation may function extracellularly also, as calpastatin has also been detected in the synovial fluid of arthritic knee joints in man. ${ }^{15-17}$ Previously, calpain was classified as an intracellular proteinase, ${ }^{14}{ }^{18}$ but more recent studies have reported the presence of $\mathrm{m}$-calpain in the extracellular matrix of the growth plate, ${ }^{19}$ the fracture callus of rats, ${ }^{20}$ and human arthritic synovial fluid. ${ }^{15-17}$ As a proteoglycan degrading capability of m-calpain has been demonstrated, ${ }^{21}$ calpain can be considered as a matrix proteinase also.

Type II collagen induced arthritis (CIA) in mice is an experimental model for inflammatory arthritis, ${ }^{22}$ and provides reproducible in vivo conditions similar to those in human rheumatoid arthritis. ${ }^{23}$ Recently, m-calpain was detected in murine CIA. ${ }^{24}$ In the present study, using the murine CIA model, we followed the appearance of $\mathrm{m}$-calpain during the time course of arthritis, evaluated the correlation between the stages of arthritis and the appearance of m-calpain, and investigated its localisation in arthritic knee joints by immunohistochemistry. We also sought the presence of $\mathrm{m}$-calpain in the arthritic mouse joint lavage by immunoelectrophoretic blotting.

\section{Materials and methods}

INDUCTION OF ARTHRITIS

Forty eight male DBA/1J mice, eight weeks old, were obtained from Seiwa Experimental Animals (Fukuoka, Japan). When they were nine weeks of age and had adapted to the new environment, CIA was induced as described previously. ${ }^{25}$ Briefly, bovine type II collagen $3 \mathrm{mg} / \mathrm{ml}$ (Cellmatrix II, Nitta Gelatin, Osaka, 
Japan) was dialysed against $0.02 \mathrm{~mol} / \mathrm{l}$ Tris $\mathrm{HCl}$ buffer, $\mathrm{pH} 8 \cdot 0$, containing $0.15 \mathrm{~mol} / \mathrm{l}$ sodium chloride $(\mathrm{NaCl})$ overnight at $4^{\circ} \mathrm{C}$, then emulsified with an equal volume of Freund's complete adjuvant (FCA). The mice were immunised intradermally at the base of the tail with $200 \mu \mathrm{g}$ of collagen and received a 'booster' injection of this emulsion 21 days later. Controls were administered an equal volume of FCA. The clinical signs of arthritis were evaluated according to the extent of swelling and erythema every other day after the booster injection. ${ }^{26}$ The animals were randomly separated into six groups (eight mice per group), and on the day of the booster injection (0 week), and 1, 2, 3, 5, and 7 weeks later, one group of mice was killed and processed for histology and immunohistochemistry.

HISTOLOGICAL ANALYSIS

Longitudinal paraffin sections ( $4 \mu \mathrm{m}$ thickness) through the knee joints were prepared after two days fixation in $10 \%$ buffered formalin and seven days decalcification in $10 \%$ buffered EDTA at $4^{\circ} \mathrm{C}$, and stained with haematoxylin and eosin, and safranin-O. Synovitis was evaluated according to previously described grading systems ${ }^{326}{ }^{27}$ appropriate to this study: intra-articular inflammation, extra-articular inflammation, synovial lining cell hyperplasia, fibrosis of the sublining cell layers, pannus formation were each graded $0-3$, where none or normal $=0$ and severe $=3$. Articular cartilage destruction was graded by a modified histological-histochemical system established by Mankin et $a l^{28}$ : structure of cartilagenormal $=0$, surface irregularities $=1$, clefts to radial zone $=2$, complete disorganisation $=3$; chondrocytes-normal $=0$, diffuse hypercellularity $=1$, cloning $=2$, hypocellularity $=3$; safranin-O staining-normal $=0$, moderate reduction $=1$, severe reduction $=2$, no dye noted $=3$; tidemark integrity-intact $=0$, crossed by blood vessels $=1$.

\section{IMMUNOHISTOCHEMISTRY}

A rabbit antibody to purified porcine $m$-calpain was prepared as previously described. ${ }^{29}{ }^{30}$ The labelled streptavidin biotin (LSAB) method was used for immunostaining. After removal of the paraffin from the sections, the endogenous peroxidase was quenched with $3 \%$ hydrogen peroxide $\left(\mathrm{H}_{2} \mathrm{O}_{2}\right)$ in water for five minutes. To block non-specific binding, the sections were incubated for 20 minutes in 5\% non-fat dry milk in $50 \mathrm{mmol} / \mathrm{l}$ Tris- $\mathrm{HCl}$ buffer, $\mathrm{pH} 7 \cdot 8$, containing $0.3 \mathrm{~mol} / 1 \mathrm{NaCl}$ and $0.1 \%$ Tween 20 (TBST) following incubation in $3 \%$ bovine serum albumin (BSA) for five minutes, and immunostaining was subsequently performed with rabbit anti-m-calpain antiserum, diluted at $1: 200$ and $1: 400$ in 5\% non-fat milk/TBST overnight. Bound antibody was targeted for 10 minutes with biotinylated anti-rabbit immunoglobulin antibody (DAKO-E432, Dako Japan Co, Ltd) diluted 1:100 in TBST containing $1 \%$ BSA. This was followed by incubation with peroxidase-conjugated streptavidin, diluted
1:80 in TBST (DAKO-P397), and the slides were developed by incubation with $0.05 \%$ diaminobenzate tetrahydrochloride (DAB) in the presence of $0.03 \% \mathrm{H}_{2} \mathrm{O}_{2}$ in $50 \mathrm{mmol} / 1$ Tris- $\mathrm{HCl}$ pH 7·6. The sections were counterstained with Mayer's haematoxylin, dehydrated and mounted. All procedures were at room temperature except the overnight incubation with the first antibody, which was at $4^{\circ} \mathrm{C}$. Negative control specimens were processed simultaneously using 1:200 dilution of normal rabbit serum (DAKO-x902) as the first antibody. Immunohistochemical staining of skeletal muscle served as positive control. ${ }^{30}$ Immunohistochemical staining for m-calpain was graded by measuring the ratio (\%) of the immunoreactivity of intra-articular inflammatory cells, synovial tissue (lining cells and subsynovial fibroblast), articular cartilage chondrocytes (scale: not stained $=0$; stained $<10 \%=1 ; \quad 10-50 \%=2 ; \quad>50 \%=3)$, and extracellular structures (scale: no staining $=0$, cartilage or synovial surface stained $=1$; intraarticular fibrin clot stained $=2$; staining of cartilage matrix $=3$ ).

\section{PREPARATION OF KNEE JOINT LAVAGE}

CIA was produced as described above. Two weeks after the booster injection, eight knee joints of four arthritic and those of control mice were cannulated with a 27 gauge needle, aspirated and washed several times with $3 \mathrm{ml}$ ice cold $20 \mathrm{mmol} / \mathrm{l}$ Tris buffer, $\mathrm{pH} \mathrm{7.5}$, containing $50 \mathrm{mmol} / 1 \mathrm{NaCl}, 1 \mathrm{mmol} / \mathrm{l} \mathrm{EGTA}$, $1 \mathrm{mmol} / 1 \mathrm{EDTA}$ and $5 \mathrm{mmol} / \mathrm{l} 2$-mercaptoethanol (buffer A). Samples were homogenised by sonication for 20 seconds three times on ice to release $m$-calpain from the intraarticular cells and cell debris, then centrifuged at $10000 \mathrm{~g}$ for 10 minutes and the supernatants filtered through disc membranes (pore size $0.22 \mu \mathrm{m}$ diameter). Samples were applied to a DEAE-cellulose column $(1.5 \mathrm{ml})$ that had been equilibrated with buffer $A$. The columns were washed several times with the same buffer, but containing $200 \mathrm{mmol} / 1 \mathrm{NaCl}$, then the protein was eluted with $2 \mathrm{ml}$ of buffer containing $400 \mathrm{mmol} / \mathrm{N} \mathrm{NaCl}$. Eluents were finally concentrated 50 -fold using a microconcentrator (Centricon-10; Amicon, Beverly, MA). The knee joint lavage experiment was repeated three times.

IMMUNOELECTROPHORETIC BLOTTING

Polyacrylamide slab gel electrophoresis (PAGE) in the presence of $0.1 \%$ sodium dodecyl sulphate (SDS) was performed with $10 \%$ resolving gels and 3\% stacking gels. After gel electrophoresis, sample proteins were transferred to a nitrocellulose membrane, according to the method of Towbin et al. ${ }^{31}$ Nitrocellulose membranes were first incubated with antim-calpain antibody (the same as that used for immunohistochemistry) and then with a peroxidase-conjugated second antibody. Antigens were visualised by peroxidase staining according to the method of Hawkes et $a l^{32}$ using $\mathrm{DAB}$ as substrate. 
STATISTICAL ANALYSIS

Data from histological and immunohistochemical gradings were entered into a computer database. The grades of synovitis and cartilage destruction were correlated with the immunohistochemical grades of m-calpain staining by simple regression analysis. Correlation coefficients ( $\mathrm{p}$ values) less than 0.002 were considered significant.

\section{Results}

CLINICAL AND HISTOLOGICAL

CHARACTERISTICS OF ARTHRITIS

In our CIA experiment, clinical signs of acute arthritis appeared five to nine days after the booster injection (except for two animals, which were excluded from the statistics) and reached a plateau between two and three weeks, after which the swelling, redness, and oedema of the paws gradually reduced. At seven weeks after the booster injection, the animals showed no sign of acute arthritis, but flexion contractures of tarsal and knee joints were remarkable. Histological findings strongly correlated with clinical signs. Before the onset of arthritis and in the control group, histological signs of inflammation were not present (fig 1A). At the peak of acute arthritis, the intra-articular space was filled with debris and fibrin clot and invaded with inflammatory cells (mostly polymorphonuclear leucocytes and mononuclear cells) and the subsynovium was massively infiltrated with these cells. Hyperplasia of the synovial lining layer, pannus formation and subsynovial fibrosis were also present, together with characteristic signs of cartilage destruction (fig 1B). At the late stage of arthritis, acute inflammatory cells disappeared from the intra-articular cavity and hyperplasia of synovial lining cells, pannus, fibrosis, and disorganisation of the articular cartilage structure became dominant (fig 1C).

\section{IMMUNOHISTOCHEMICAL LOCALISATION OF} M-CALPAIN

Only weak or no m-calpain immunostaining in the subsynovium was present before the onset of arthritis and in control animals (fig 2A). Staining for m-calpain was absent in all sections incubated with normal rabbit serum as primary antibody (fig $2 \mathrm{E}$ ). In contrast, $\mathrm{m}$-calpain was detectable in all sections from arthritic animals (fig 2B-D). During the acute stage of arthritis, m-calpain was immunolocalised to the intra-articular space, the synovial tissue, and the articular cartilage. Strong intra-articular staining for m-calpain was detected on the surface of the cartilage and synovial cells, in the cytoplasm of the inflammatory cells and in the surrounding cell and matrix debris. Positive staining was present in the proliferating synovial lining cells and subsynovial fibroblasts. In addition to its location at the cartilage surface, m-calpain was observed in the lacunae of the chondrocytes and in the extracellular matrix in focal areas of the articular cartilage. Pannus covering the cartilage surface also showed marked positivity (fig 2B, C). In the late stage of arthritis, $\mathrm{m}$-calpain was still detectable in the synovial tissue, remaining articular cartilage, and

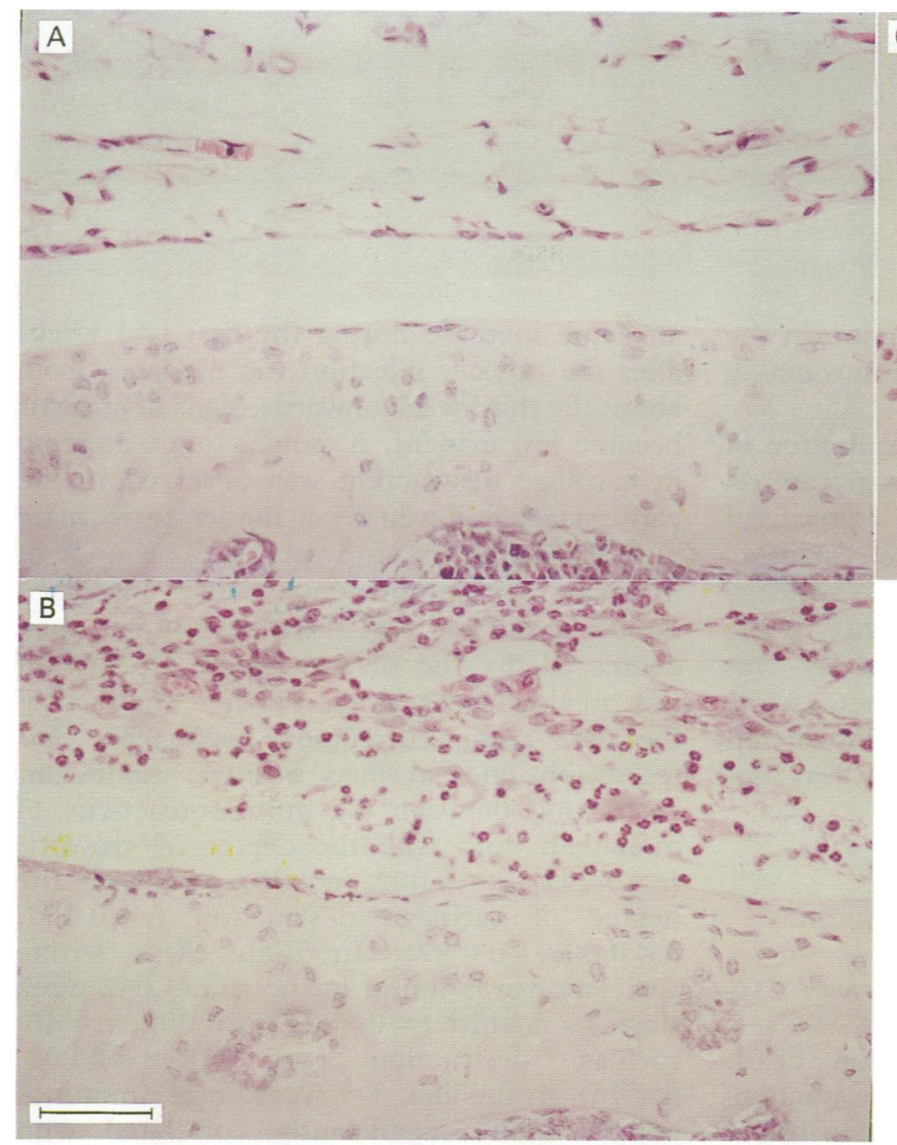

Figure 1 Histological characteristics in different stages of collagen induced arthritis. A: Section of a non-arthritic knee joint, showing normal cartilage and synovial tissue. B: Section of an acute arthritic knee joint, showing inflammatory cell infiltration into the synovial tissue and invasion into the intra-articular space with adhesion to the cartilage surface. C: Section of a late stage arthritic knee joint, showing proliferation of the synovial tissue, pannus formation, and cartilage destruction. Haematoxylin and eosin stained. Horizontal bar represents $50 \mathrm{\mu m}$. 


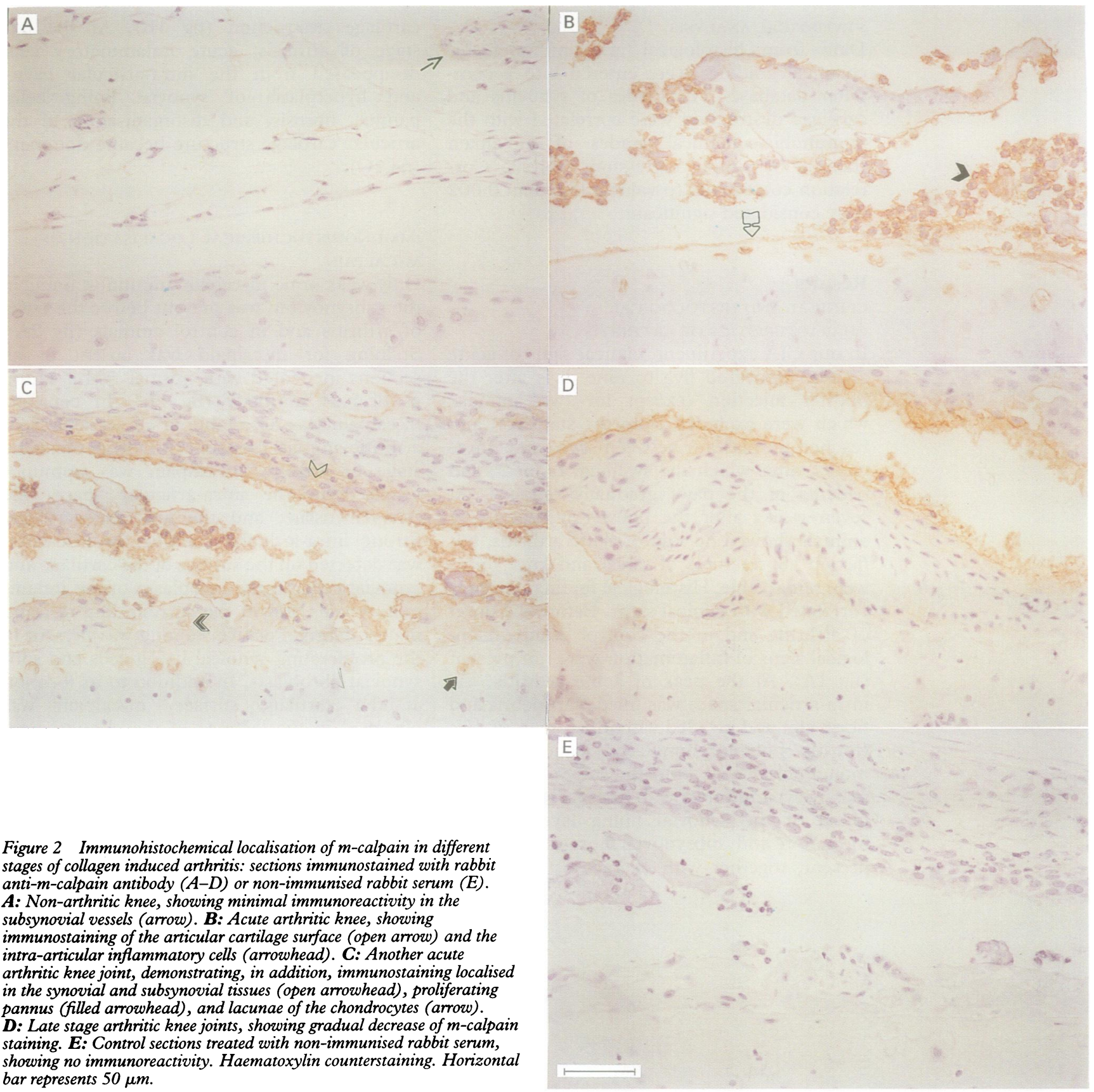

CORRELATION OF IMMUNOHISTOCHEMICAL STAINING OF M-CALPAIN AND THE HISTOLOGICAL COURSE OF ARTHRITIS AND CARTILAGE DESTRUCTION

Based on semiquantitative evaluation, histological grades of arthritis in the knee joints of type II collagen immunised mice demonstrated an acute increase during the first two weeks after the booster injection (fig 3); later, from about the third week onwards, signs of arthritis became less evident. A similar quick increase in cartilage destruction was observed in the early stage, followed by a moderate increase until the end of the study period. The grade of m-calpain immunoreactivity also increased rapidly in the first part of the experiment, then decreased, by the seventh week, to $50 \%$ of the previous peak level. Further analyses of the data using correlation coefficients and regression lines verified positive, significant correlation between the immunoreactivity of $\mathrm{m}$-calpain both with the degree of synovitis $(r=0.741, \mathrm{p}<0.002, \mathrm{n}=92)$ and with the degree of cartilage destruction $(r=0.554$, $\mathrm{p}<0.002, \mathrm{n}=92)$. In both cases strong correlation was found in the acute, $0-2$ week stage (synovitis: $r=0.882, \mathrm{p}<0.002, \mathrm{n}=46$; cartilage destruction: $r=0.796, p<0.002$, $\mathrm{n}=46$ ). In the late, $3-7$ week stage, immunoreactivity still significantly correlated with 


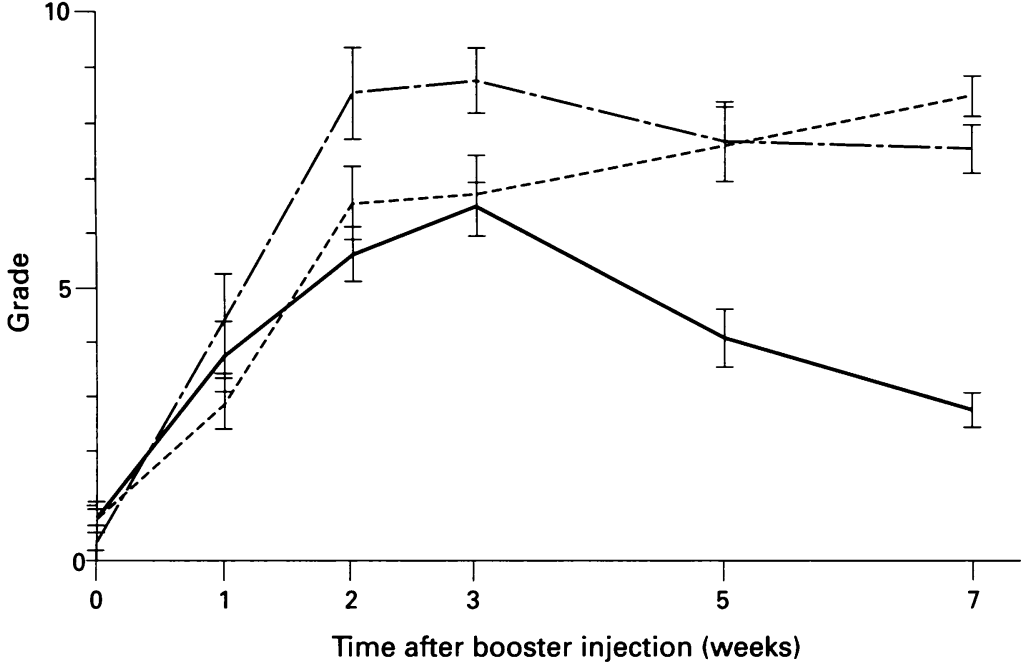

Figure 3 Time course of synovitis (-- -), cartilage destruction (----), and m-calpain immunoreactivity (—) in collagen induced arthritis (mean, SEM; $n=14$ ).

synovitis $(r=0.530, \mathrm{p}<0.002, \mathrm{n}=46)$, but not with cartilage destruction $(r=0.292$, $0.05<\mathrm{p}<1, \mathrm{n}=46$ ).

DEMONSTRATION OF M-CALPAIN IN ARTHRITIC KNEE JOINT LAVAGE BY

IMMUNOELECTROPHORETIC BLOTTING

Non-arthritic and arthritic knee joint lavage of mice were processed simultaneously. Figure 4 shows the results. The arthritic knee joint lavage demonstrated a positive band at $80 \mathrm{kDa}$, which corresponds to the m-calpain large subunit, and a band at $67 \mathrm{kDa}$, which may be assumed to be a partially degraded fragment of the same protein. ${ }^{15}$ Immunoelectrophoresis blots of samples from non-arthritic knee joint lavage did not demonstrate any banding. The same results were obtained three times.

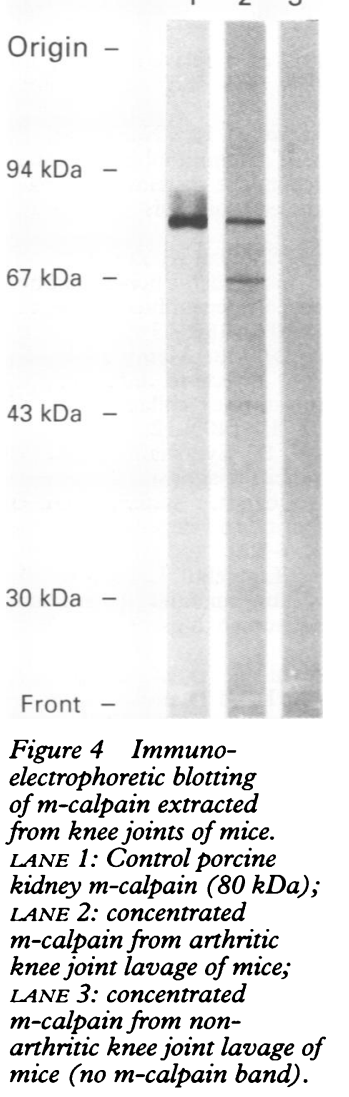

\section{Discussion}

The calpain-calpastatin system is relatively new, as the history of its discovery dates back little more than a decade. ${ }^{13}$ Calpain is also 'young' in terms of molecular evolution as, presumably, gene fusion resulted in a unique multidomain cysteine proteinase ${ }^{34}$ with highly regulated, selective, and limited activity. Although calpain has generally been considered to be an intracellular enzyme, it has now been detected in the extracellular matrix of growth cartilage, ${ }^{19}$ in fracture callus, ${ }^{20}$ and in the synovial fluids of arthritic patients. ${ }^{15-17}$ Furthermore, it has been demonstrated that calpain is a potent proteoglycanase, as it demonstrates a dose-dependent and limited proteolytic activity on proteoglycan, ${ }^{21}$ the major extracellular component of cartilage. More recently, the presence of $\mathrm{m}$-calpain has been reported in murine collagen induced arthritis. $^{24}$

In the present study, m-calpain was detected using the LSAB method for immunohistochemistry, and applied to paraffin sections from CIA mice to provide correct morphology. In arthritic joints, marked $\mathrm{m}$-calpain immunostaining was observed on the synovial and cartilage sides, and in the intra-articular space-a distribution comparable to the localisation of stromelysin and collagenase in CIA of rats. ${ }^{35}$ Stromelysin, which is believed to be the major cartilage matrix degrading metalloproteinase, was immunolocalised in both the synovium and articular cartilage, similar to our findings with m-calpain. Stromelysin and collagenase were also present on the surface of cartilage at the cartilagepannus junction, while m-calpain in this study was detectable on almost the entire articular surface. There was a further strong intraarticular positivity for calpain, but not for stromelysin and collagenase. ${ }^{35}$ One explanation for this could be that calpain was not washed out during fixation and decalcification, as the joints were not required to be open for these procedures in our experiment.

The large series of arthritic animals and the semiquantitative grading system applied in our investigation provided the opportunity for statistical analyses. The significant, positive correlation between the immunoreactivity of m-calpain and the stages of arthritis and cartilage destruction-especially in the acute stage- suggests that calpain can be induced by inflammatory mediators and may take part in the early progression of the arthritis. This may occur in two ways: calpain itself may initiate the cartilage matrix digestion, or it may activate some other latent, potentially degradative enzymes. The presence of calpain in the late stage of the arthritic process, although at reduced levels, suggests a gradual downregulation.

An important question is, which cells are responsible for production of calpain under arthritic conditions? Studies on human rheumatoid arthritic and osteoarthritic synovial tissue $^{16}$ revealed the presence of calpains mainly in the synovial lining layers, with a little in the subsynovium. Certain features of the animal model of arthritis agree with these findings and suggest that synovial cells synthesise calpain. Recently, the responsibility of human arthritic synovial cells for the synthesis of calpain was further characterised, and it was clearly demonstrated that synovial fibroblasts, but not phagocytic synovial macrophages, are involved in this process. ${ }^{36}$ Although our current investigation in a CIA model did not differentiate between types of synovial cells, the observed similar characteristics of immunolocalisation of m-calpain in the synovium support the relevance of this experimental arthritis model to human rheumatoid arthritis. In our study, as in a previous report, ${ }^{24}$ $\mathrm{m}$-calpain was immunolocalised on the cartilage surface, matrix, and lacunae of the chondrocytes in the joints of arthritic mice. However, as immunostaining was observed mainly on the cartilage surface and in the superficial layers, was restricted to focal areas and was not clearly colocalised with the loss of proteoglycan on safranin-O sections, these findings could simply reflect limited antibody penetration into the cartilage matrix; the active involvement of chondrocytes still remains uncertain. A third possible source of calpain is 
the acute inflammatory cells, polymorphonuclear leucocytes, and mononuclear cells present in the acute stages of both rheumatoid $^{37}{ }^{38}$ and collagen induced arthritis. ${ }^{39}$ These cells are highly activated and have been reported to contain proteolytic enzymes ${ }^{9} 11+0$ and calpains. ${ }^{33+1}$ Our immunohistochemical findings support these results, as $\mathrm{m}$-calpain was detected in the cytoplasm of polymorphonuclear cells which had invaded the intraarticular space and were surrounded with immunopositive cellular and matrix debris. Positive m-calpain immunoblotting of the arthritic knee joint lavage samples provides further proof that m-calpain is localised in the intra-articular cavity. As a result of secretion or release from dead cells, it can be partially intracellular, in addition to being extracellular. Further analysis will be required to determine if its location is predominantly extra- or intracellular.

One of the most exciting findings from studies of cartilage proteoglycan metabolism is the identification of the specific enzyme 'aggrecanase', which is assumed to make the first cleavage of human aggrecan core protein in vivo at the Glu 373-Ala 374 bond within the interglobular domain between G1 and G2 domains, producing two major primary fragments released into the joint fluids under both normal and pathological conditions. ${ }^{42}$ Although the preferred cleavage site for $\mu$-calpain is the C-terminal of the $\mathrm{G} 2$ domain, calpains apparently cleave the interglobular domain, much like the matrix proteinases (MMP) and aggrecanase under conditions of high enzyme activity. ${ }^{43}$ Interestingly, studies of cartilage explant cultures stimulated by IL-1 or retinoic acid have suggested the existence of two converging pathways of cartilage proteoglycan breakdown - one inhibited by cathepsin $B$ inactivator and the other not. An inhibitor of MMP was inhibitory to both reactions. ${ }^{44}$

In conclusion, our results support the hypothesis that calpain is actively involved in the pathological process leading to inflammatory arthritis, by acting as a neutral matrix proteinase, by enhancing other pathways, or both

The authors thank Mr Yoichi Tani for expert technical advice and Dr Patrick Hughes for careful reading of the manuscript.

1 Hasty K A, Pourmotabbed T F, Goldberg G I, et al. Human neutrophil collagenase: a distinct gene product with homology to other matrix metalloproteinases. $\mathcal{F} \mathrm{Biol} \mathrm{Chem}$ 1990; 265: $11421-4$.

2 Goldberg G I, Wilhelm S M, Kronberger A, Bauer E A, Grant G A, Eisen A Z. Human fibroblast collagenase: complete primary structure and homology to an oncogene complete primary structure and homology to an oncogene
transformation-induced rat protein. $\mathcal{F}$ Biol Chem 1986; transformation

3 Okada Y, Shinmei M, Tanaka O, et al. Localization of matrix metalloproteinase 3 (stromelysin) in osteoarthritic cartilage and synovium. Lab Invest 1992; 66: 680-90.

4 Pelletier J-P, Faure M-P, DiBattista J A, Wilhelm S, Visco D, Martel-Pelletier J. Coordinate synthesis of stromelysin, interleukin-1, and oncogene proteins in experimental osteoarthritis: an immunohistochemical study. Am ₹ Pathol 1993; 142: 95-105.

5 Wilhelm S M, Collier I E, Kronberger A, et al. Human skin fibroblast stromelysin: structure, glycosylation, substrate specificity, and differential expression in normal and tumorigenic cells. Proc Natl Acad Sci USA 1987; 84 6725-9.

6 Hibbs M S, Hasty $K$ A, Seyer J M, Kang A $H$ Mainardi C L. Biochemical and immunological characterization of the secreted forms of human characterization of the secreted forms of human
7 Mohtai M, Smith R L, Schurman D J, et al. Expression of 92-kD type IV collagenase/gelatinase (gelatinase B) in osteoarthritic cartilage and its induction in normal human articular cartilage by interleukin 1. F Clin Invest 1993; 92: articular $179-85$.

8 Pelletier J-P, Mineau F, Faure M-P, Martel-Pelletier J. Imbalance between the mechanisms of activation and Imbalance between the mechanisms of activation and
inhibition of metalloproteinases in the early lesions of inhibition of metalloproteinases in the early lesions of
experimental osteoarthritis. Arthritis Rheum 1990; 33:

9 Schalkwijk J, Joosten L A B, van den Berg W B, van de Putte L B A. Experimental arthritis in C 57 black/6 normal and beige (Chediak-Higashi) mice: in vivo and in vitro observation on cartilage degradation. Ann Rheum Dis 1988; 47: 940-6.

10 Trabandt A, Gay R E, Fassbender H-G, Gay S. Cathepsin B in synovial cells at the site of joint destruction in rheumatoid arthritis. Arthritis Rheum 1991; 34: in rheumat

11 Moore A R, Iwamura H, Larbre J P, Scott D L, Willoughby D A. Cartilage degradation by polymorphonuclear leucocytes: in vitro assessment of the pathogenic mechanisms. Ann Rheum Dis 1993; 52: 27-31.

2 Kowanko I C, Ferrante A. Granulocyte-macrophage colony-stimulating factor augments neutrophil-mediated cartilage degradation and neutrophil adherence. Arthritis Rheum 1991; 34: 1452-60.

13 Murachi $T$, Tanaka K, Hatanaka $M$, Murakami T. Intracellular $\mathrm{Ca}^{2+}$-dependent protease (calpain) and its highmolecular-weight endogenous inhibitor (calpastatin). $A d v^{\prime}$ Enzyme Regul 1981;19: 407-24.

14 Murachi T. Calpain and calpastatin. Trends Biochem Sci 1983; 8: $167-9$.

15 Suzuki K, Shimizu K, Hamamoto T, Nakagawa Y, Hamakubo T, Yamamuro T. Biochemical demonstration of calpain and calpastatin in osteoarthritic synovial fluid. Arthritis Rheum 1990; 33: 728-32.

16 Yamamoto S, Shimizu K, Shimizu K, Suzuki K, Nakagawa Y, Yamamuro T. Calcium-dependent cysteine proteinase (calpain) in human arthritic svnovial joints. Arthritis Rheum 1992; 35: 1309-17.

17 Fukui I, Tanaka K, Murachi T. Extracellular appearance of calpain and calpastatin in the synovial fluid of the knee joint. Biochem Biophys Res Commun 1989;162: 559-66.

18 Pontremoli S, Melloni E. Extralysosomal protein degradation. Ann Rev Biochem 1986; 55: 455-81

19 Shimizu K, Hamamoto T, Hamakubo T, et al. Immunohistochemical and biochemical demonstration of calciumdependent cysteine proteinase (calpain) in calcifying cartilage of rats. $\mathcal{F}$ Orthop Res 1991; 9: 26-36

20 Nakagawa Y, Shimizu K, Hamamoto T, Suzuki K, Ueda M, Yamamuro T. Calcium-dependent neutral proteinase (calpain) in fracture healing in rats. F Orthop Res 1994; 12: 58-69.

21 Suzuki K, Shimizu K, Hamamoto T, Nakagawa Y, Murachi T, Yamamuro T. Characterisation of proteoglycan degradation by calpain. Biochem f 1992; 285: glycan degt
$857-62$.

22 Courtenay J S, Dallman M J, Dayan A D, Martin A, Mosedale B. Immunisation against heterologous type II collagen induces arthritis in mice. Nature 1980; 283: 666-8.

23 Trentham D. Collagen arthritis as a relevant model for rheumatoid arthritis: evidence pro and con. Arthritis Rheum 1982; 25: 911-6.

24 Fujimori Y, Shimizu K, Suzuki K, Nakagawa Y, Yamamoto $S$, Yamamuro $T$. Immunohistochemical demonstration of calcium-dependent cysteine proteinase (calpain) in collagen-induced arthritis in mice. $Z$ Rheumatol 1994; 53: 72-5.

25 Fujimori Y, Nakamura T, Ijiri S, Shimizu K, Yamamuro T. Heterotopic bone formation induced by bone morphoHeterotopic bone formation induced by bone morphogenetic protein in mice with collagen-induced ar
Biochem Biophys Res Commun 1992; 186: 1362-7.

26 Griswold D E, Hillegass L M, Meunier P C, DiMartino $M$ J, Hanna $N$. Effect of inhibitors of eicosanoid metabolism in murine collagen-induced arthritis. Arthritis Rheum 1988; 31: 1406-12.

27 Goldenberg D L, Cohen A S. Synovial membrane histopathology in the differencial diagnosis of rheumatoid arthritis, gout, pseudogout, systemic lupus erythematosus, infectious arthritis and degenerative joint disease. Medicine 1978; 57: 239-52.

28 Mankin H J, Dorfman H, Lippiello L, Zarins A. Biochemical and metabolic abnormalities in articular cartilage from osteo-arthritic human hips. $f$ Bone foint Surg Am 1971; 53: 523-37.

29 Kitahara A, Sasaki T, Kikuchi T, et al. Large-scale purification of porcine calpain I and II and comparison of proteolytic fragments of
(Tokyo) 1984; 95: 1759-66.

30 Yoshimura N, Ohtuki H, Hamakubo T, Kitahara A, Koshimura N, Ohtuki H, Hamakubo T, Kitahara A,
Kannagi R, Murachi T. Distribution of calpain in various organs of the rat: an immunohistochemical study. Biomed Res 1984; 5: 419-24.

31 Towbin H, Staehelin T, Gordon J. Electrophoretic transfer of proteins from polyacrylamide gels to nitrocellulose sheets: procedure and some applications. Proc Natl Acad Sci USA 1979; 76: 4350-4.

32 Hawkes R, Niday E, Gordon J. A dot-immunobinding assay for monoclonal and other antibodies. Anal Biochem 1982; 119: $142-7$

33 Takano E, Park Y-H, Kitahara A, Yamagata Y, Kannagi R, Murachi T. Distribution of calpains and calpastatin in human blood cells. Biochem Int 1988; 16: 391-5. 
34 Ohno S, Emori Y, Imajoh S, Kawasaki H, Kisaragi M, Suzuki $K$. Evolutionary origin of a calcium-dependent
protease by fusion of genes for a thiol protease and a protease by fusion of genes for a thiol protease and
calcium-binding protein? Nature $1984 ; 312: 566-70$.

35 Hasty K A, Reife R A, Kang A H, Stuart J M. The role of stromelysin in the cartilage destruction that accompanies inflammatory arthritis. Arthritis Rheum 1990; 33: 388-97.

36 Yamamoto S, Shimizu $K$, Niibayashi $H$, Yasuda $T$, Yamamuro $\mathrm{T}$. Immunocytochemical demonstration of calpain in synovial cells in human arthritic synovial joints. Biomedical Res 1994; 15: 77-88.

37 Kulka J P, Becking D, Ropes M W, Bauer W. Early joint lesions in rheumatoid arthritis: report of eight cases with knee biopsies of lesions of less than one year's duration. Acta Pathol Lab Med 1955; 59: 129-50.

$38 \mathrm{Mohr}$ W, Pelster B, Wessinghage D. Polymorphonuclear granulocytes in rheumatic tissue destruction. Rheumatol Int 1984; 5: 39-44.

39 Caulfield J P, Hein A, Dynesius-Trentham R, Trentham D E. Morphologic demonstration of two stages in the development of type II collagen-induced arthritis. Lab Invest 1982; 46: 321-43.
40 Lowther D A, Sriratana A, Bartholemew J S. The role of serine proteinase in cartilage damage. $\mathcal{F}$ Rheumatol Suppl 1987; 14: 49-51.

41 Fukui I, Toyohara $H$, Ito $K$, Hamakubo $T$, Murachi $T$. Molecular and catalytic characterization of intact heterodimer and derived monomeric calpains isolated under different conditions from pig polymorphonuclear leucocytes. Biochemistry 1988; 27: 3260-7.

42 Sandy J D, Flannery C R, Neame P J, Lohmander L S. The structure of agorecan fragments in human synovial fluid. Evidence for the involvement in osteoarthritis of a novel proteinase which cleaves the Glu 373-Ala 374 bond of the interglobular domain. $¥$ Clin Invest 1992; 89: 1512-6.

43 Suzuki K, Shimizu K, Sandy J D. Aggrecan degradation by calpain [abstract]. 40th Annual Meeting, Orthopaedic Research Society, 21-24 February 1994; New Orleans, Research Society,
Louisiana, USA.

44 Buttle D J, Handley C J, Ilic M Z, Saklatvala J, Murata M, Barrett A J. Inhibition of cartilage proteoglycan release by a specific inactivator of cathepsin B and an inhibitor of matrix metalloproteinases. Evidence for two converging pathways of chondrocyte-mediated proteoglycan degradation. Arthritis Rheum 1993; 36: 1709-17. 